\title{
OBSERVATIONS ON PARAMECIUM OCCUPYING ARBOREAL STANDING WATER IN COSTA RICA ${ }^{1}$
}

\author{
John Vandermeer, ${ }^{2}$ John Addicott, ${ }^{2}$ Ayesha Andersen, ${ }^{3}$ John Kitasako, ${ }^{4}$ \\ David Pearson, ${ }^{5}$ Charles Schnell, ${ }^{6}$ and Henry Wilbur ${ }^{2}$ \\ Organization for Tropical Studies, La Selva, Costa Rica
}

\begin{abstract}
Some observations on the natural history of the Paramecium-Heliconia system are presented. The pattern of distribution in the wet season seems to be either a random colonization or a colonizing bias toward younger bracts, but ultimately the mosquito larvae in the older bracts build up, resulting in the death of the local Paramecium population. The dry season pattern appears to be different at least in that there are very few mosquito larvae.

The observation of Maguire and Belk (1967) that Paramecium do not occur in bromeliads was repeated. Experiments were performed demonstrating that if Paramecium do get to bromeliads, the biological interactions between the Paramecium and the regular microfauna of the bromeliad are such that the Paramecium are driven to extinction.
\end{abstract}

Maguire and Belk (1967) and Maguire, Belk, and Wells (1968) pointed out the existence of Paramecium in the water-filled bracts of Heliconia caribaea Lamarck on Puerto Rico. The dispersal of Paramecium from one inflorescence to another was demonstrated to be due to the movements of snails (Caracolus), but other dispersal agents such as hummingbirds and insects were not ruled out. The abundance of Paramecium in a bract was shown to be controlled by the number of mosquito larvae (Culex americanus) in that bract. Although Paramecium could have reached many nearby bromeliads, it was never found in this habitat, confirming Laessle's (1961) observations on Jamaican bromeliads. Maguire presumed that the absence of Paramecium from bromeliads would therefore be due to its "exclusion or elimination . . . by biological interactions."

In this report we present observations on the microdistribution of Paramecium in some Costa Rican container habitats and the causes for the absence of Paramecium in bromeliads.

Observations were made during the wet season (August 1969) on samples taken from the following sources: Heliconia imbricata (Kuntze) Baker, $\boldsymbol{H}$. latispatha Bentham, Calathea insignis Petersen, and several species of bromeliads. During the dry season (March 1971) observations were made on Heliconia wagneriana Petersen. The wet season samples were taken on Finca La Selva, Puerto Viejo, on the Atlantic lowlands of Costa Rica, and the dry season

\footnotetext{
${ }^{1}$ Received June 11, 1971; accepted October 1, 1971.

${ }^{2}$ Present address: Department of Zoology, University of Michigan, Ann Arbor.

${ }^{3}$ Present address: Department of Genetics, University of California, Berkeley.

${ }^{4}$ Present address: Department of Life Sciences, University of California, Riverside.

${ }^{5}$ Present address: Department of Zoology, University of Washington, Seattle.

${ }^{6}$ Present address: Biological Laboratories, Harvard University, Cambridge, Massachusetts.
}

samples were from the grounds of the Interamerican Institute of Scientific Agriculture (IICA), Turrialba. All identifications of Heliconia were accomplished with the help of Smith's monograph on Heliconia (Smith 1968). All habitats sampled except for bromeliads contained Paramecium. At least two types of Paramecium are involved, but the identification as to species and syngen has not been completed.

\section{Seasonal Variability in Microdistribution}

In the moist areas of Costa Rica with which we are familiar, Heliconia latispatha and $H$. imbricata flower in the wet season while $H$. wagneriana flowers in the dry season. Inflorescences of Calathea insignis are present in both seasons, but they are comparatively rare. The sampling of Heliconia bracts was done such that at least two bracts were sampled from each inflorescence, one old and the other young. The structure of these Heliconia inflorescences is such that the young bracts are always above the old bracts.

We have made two general observations concerning the microdistribution and abundance of Paramecium in the bracts of Heliconia and Calathea during the wet season. First, if Paramecium was present in some bracts of an inflorescence, but absent from others, it was absent from the older bracts, never from the younger ones. Second, there is a significant negative correlation between the abundance of mosquito larvae and the abundance of Paramecium, just as Maguire et al. (1968) found on Puerto Rico. Our observations are presented in Table 1 .

The above two observations lead to the following generalization about the dynamics of the Paramecium-Heliconia-mosquito system during the wet season. Heliconia bracts appear to be favorable habitats for the growth of Paramecium populations, and any propagule reaching a bract is likely to successfully colonize it. This appears to be particularly true of young bracts. Other bracts on the same inflorescence 
TABLE 1. Number of bracts of $\boldsymbol{H}$. imbricata containing mosquito larvae at one of three relative densities of Paramecium $\left(\chi^{2}=22.91\right.$, df $\left.=2, P<.005\right)$

\begin{tabular}{lcccc}
\hline \hline & \multicolumn{3}{c}{ Paramecium density } \\
\cline { 2 - 4 } & & Abundant & Rare & Absent \\
\hline $\begin{array}{c}\text { Mosquito } \\
\text { larvae }\end{array}$ & Present & 0 & 1 & 8 \\
& Absent & 11 & 6 & 4 \\
\hline
\end{tabular}

can then be colonized either by a new invasion or by the washing of individuals from bract to bract due to the frequent rains. Mosquito larvae may appear in the bracts with time, and their effect upon Paramecium abundance will be most strongly noted in the older bracts. At least in the wet season it appears that mosquito larvae are significant factors in the control of the distribution and abundance of Paramecium.

There appears to be a different pattern during the dry season, due probably to the relatively low densities of mosquito larvae. In the dry season Paramecium is not differentially eliminated from the lower bracts as it was during the wet season. Of nine inflorescences sampled two had Paramecium in the lower bract but none in the upper bract, four had both top and bottom colonized, three had no Paramecium in either bract, and none had Paramecium exclusively in the top bract. Furthermore, 27 bracts were sampled every other day for a period of 10 days, enabling the observation of numerous colonization events. The results of these observations, presented in Table 2 , show clearly that the probability of a bract being colonized at any time is independent of whether or not another bract on the same inflorescence already contains Paramecium. Thus, during the dry season Paramecium appears to colonize the bracts of an inflorescence randomly and its population levels do not appear to be greatly influenced by the low level of predation.

The availability of Heliconia bract habitat varies considerably throughout the year. The wet season plant, $H$. imbricata, is very common compared to $H$. wagneriana, the dry season plant. The total available habitat may in fact be nearly equivalent in the two seasons due to the heavy predation when bracts are abundant. Many of the Heliconia populations occur at some distance from other suitable Paramecium habitats, such as permanent ponds and streams.

\section{On the Absence of Paramecium in Bromeliads}

Although Paramecium is frequently encountered in the bracts of Heliconia, neither Maguire and Belk (1967), Laessle (1961), nor we have found it in bromeliads, a habitat to which Paramecium is ca-
TABLE 2. Number of noncolonized bracts that became colonized in a 2-day period in one of two classes: (1) member of a flower head in which no other bracts were colonized, or (2) member of a flower head in which one or more bracts were colonized

\begin{tabular}{lcc}
\hline \hline & $\begin{array}{c}\text { Number } \\
\text { unoccupied } \\
\text { on day } x\end{array}$ & $\begin{array}{c}\text { Number unoccupied } \\
\text { on day x that became } \\
\text { occupied by day } x+2\end{array}$ \\
\hline $\begin{array}{c}\text { No other bract in } \\
\text { inflorescence } \\
\text { occupied } \\
\begin{array}{c}\text { Other bracts in } \\
\text { inflorescence } \\
\text { occupied }\end{array}\end{array}$ & 39 & 7 \\
\hline
\end{tabular}

pable of dispersing and one which would appear suitable because of the permanent water supply in the bromeliad tank. We attempted to determine experimentally whether or not Paramecium is capable of living in bromeliads at all, and if not what the nature of the exclusion might be.

We utilized two approaches. The first approach allowed us to determine if Paramecium could exist in bromeliads at all. For this we divided a sample of 18 bromeliads equally, washing the first group with soapy water and rinsing in river water, and leaving the other group untreated so that their water and invertebrate community were left in their normal condition. The washed bromeliads were then filled with river water. A vigorous Paramecium culture was then added to all bromeliads, and the state of the Paramecium population noted after 3 and 7 days. The bromeliads were of several undetermined species and were allotted at random to the two treatments. The results are shown in Tables 3 and 4 . We conclude from these results that Paramecium is capable of living in bromeliads, but that there is some type of biological interaction which excludes Paramecium from the bromeliad communities. Two mechanisms of exclusion seem possible. The first is that the bromeliad produces a compound that builds up in the tank and is toxic to Paramecium. The second possibility is that significant interactions between Paramecium and the rest of the microfauna in the bromeliad are excluding Paramecium from the community.

Our second approach was designed to differentiate between these two possible mechanisms of exclusion. Water was removed from several bromeliads, half of which was filtered to remove the smallest ciliates, while the other half was left untreated. Five petrie dishes were set up for each treatment; to each was added fluid and an innoculum of Paramecium derived from $H$. imbricata. A third treatment, consisting of filtered water from the bracts of $\boldsymbol{H}$. imbricata, was set up in the same manner.

Observations were made frequently after initiation of the experiment but it was not until the beginning 
TABLE 3. Frequency of occurrence of Paramecium in treated and untreated bromeliads after 3 days have elapsed

\begin{tabular}{lccc}
\hline \hline & \multicolumn{3}{c}{ Paramecium abundance } \\
\cline { 2 - 4 } & $\begin{array}{c}\text { Absent or } \\
\text { rare }\end{array}$ & Common & Abundant \\
\hline Bromeliads washed & 2 & 3 & 4 \\
Bromeliads unwashed & 9 & 0 & 0 \\
\hline
\end{tabular}

TABLE 4. Frequency of occurrence of Paramecium in treated and untreated bromeliads after 7 days had elapsed

\begin{tabular}{lccc}
\hline \hline & \multicolumn{2}{c}{ Paramecium abundance } \\
\cline { 2 - 4 } & $\begin{array}{c}\text { Absent or } \\
\text { rare }\end{array}$ & Common & Abundant \\
\hline Bromelaids washed & 3 & 3 & 3 \\
Bromeliads unwashed & 9 & 0 & 0 \\
\hline
\end{tabular}

TABLE 5. Average density of Paramecium in three treatments (see text for explanation)

\begin{tabular}{lccc}
\hline \hline & \multicolumn{2}{c}{ August 4 } & \multicolumn{2}{c}{ August 5 } \\
\cline { 2 - 4 } & Morning & Afternoon & Morning \\
\hline Filtered bromeliad & 1.6 & .8 & .4 \\
Unfiltered bromeliad & .2 & .0 & .0 \\
Filtered Heliconia & 1.2 & .8 & .6 \\
\hline
\end{tabular}

of the fourth day that any significant declines in the Paramecium populations were observed. At this point the populations were qualitatively scored -2 for com- mon, 1 for rare, and 0 for absent-and the average score for each treatment was computed. This was done three times at approximately 12-hour intervals during the fourth day. The results are pressented in Table 5. The fact that significant changes in population density were not observed until the fourth day indicates that toxic compounds are probably not involved in the exclusion. On the other hand, the decline of the populations in the unfiltered fluid relative to that of the filtered bromeliad and filtered Heliconia fluid indicates that interactions between Paramecium and the microcommunity of bromeliads is the most likely cause of the exclusion of Paramecium from bromeliads.

\section{ACKNOWLEDGMENTS}

We wish to thank the members of the OTS advanced population biology course (summer 1969) for stimulating discussion and criticism. Also special thanks go to IICA Turrialba and especially Jorgé Montoya for providing facilities for the observations made in the dry season of 1971. Part of this work was supported by the University of Michigan Rackham Faculty Research Grant No. 333420.

\section{Literature Cited}

Laessle, A. M. 1961. A micro-limnological study of Jamaican bromeliads. Ecology 42:499-517.

Maguire, B., Jr., and D. Belk. 1967. Paramecium transport by land snails. J. Protozoology 14:445-447.

Maguire, B., Jr., D. Belk, and G. Wells. 1968. Control of community structure by mosquito larvae. Ecology 49:207-210.

Smith, R. R. 1968. A taxonomic revision of the Genus Heliconia in middle America. Ph.D. Thesis, University of Florida, Gainesville. 